\title{
Pengaruh Model Pembelajaran Problem Solving Terhadap Kemampuan Komunikasi Matematis Ditinjau dari Gender
}

\author{
H. Hodiyanto \\ Program Studi Pendidikan Matematika, IKIP PGRI Pontianak, Jalan Ampera No 8 Pontianak \\ Kalimantan Barat, Indonesia. \\ Corresponding Author. Email: hodiyanto@ikippgriptk.ac.id \\ Received: 29 August 2017; Revised: 20 December 2017; Accepted: 21 December 2017
}

\begin{abstract}
Abstrak
Tujuan penelitian ini adalah untuk mengetahui: (1) manakah kemampuan komunikasi matematis siswa yang lebih baik antara model pembelajaran problem solving (PS) dan model pembelajaran langsung; (2) manakah kemampuan komunikasi matematis siswa yang lebih baik antara kelompok laki-laki dan perempuan; (3) interaksi antara model pembelajaran dan gender terhadap kemampuan komunikasi matematis. Metode penelitian yang digunakan adalah penelitian eksperimental semu. Populasi dalam penelitian ini adalah siswa kelas VII SMP Negeri 02 Mojolaban Sukoharjo. Pengambilan sampel dilakukan dengan teknik cluster random sampling. Instrumen untuk mengumpulkan data adalah tes kemampuan komunikasi matematis. Pengujian hipotesis pada penelitian ini menggunakan anova dua jalan dengan sel tak sama. Hasil penelitian menunjukkan bahwa: (1) kemampuan komunikasi matematis siswa lebih baik jika diberikan model pembelajaran PS dibandingkan model pembelajaran langsung; (2) tidak terdapat perbedaan kemampuan komunikasi matematis siswa antara siswa laki-laki dan perempuan; (3) tidak terdapat interaksi antara model pembelajaran dan gender terhadap kemampuan komunikasi matematis.
\end{abstract}

Kata Kunci: problem solving, komunikasi matematis, gender

\section{The Effect of Problem Solving Learning Model Toward Mathematical Communication Ability Viewed from Gender}

\begin{abstract}
The purpose of this research was to know: (1) which one better mathematical communication ability between student teached by problem solving model (PS) and direct learning model; (2) which one better mathematical communication ability between groups of male and female students; (3) interaction between learning model and gender to mathematical communication skill. The research method used was quasi experimental research. The population in this research were the seventh grade students of SMP Negeri 02 Mojolaban Sukoharjo. Sampling was done by cluster random sampling technique. The instrument for collecting data was a test of mathematical communication ability. Hypothesis testing in this study used two way anova analysis with unequal cells. Based on the result of research, it was found that: (1) students' mathematical communication ability was better if given PS learning model compared to direct learning model; (2) there was no difference of students' mathematical communication ability between male and female students; (3) there is no interaction between learning model and gender to mathematical communication ability.
\end{abstract}

Keywords: problem solving, mathematical communication, gender

How to Cite: Hodiyanto, H. (2017). Pengaruh model pembelajaran problem solving terhadap kemampuan komunikasi matematis ditinjau dari gender. Jurnal Riset Pendidikan Matematika, 4(2), 219-228. doi:http://dx.doi.org/10.21831/jrpm.v4i2.15770

Permalink/DOI: http://dx.doi.org/10.21831/jrpm.v4i2.15770 


\title{
Jurnal Riset Pendidikan Matematika, 4 (2), 2017 - 220
}

\author{
H. Hodiyanto
}

\section{PENDAHULUAN}

Matematika adalah ilmu yang erat kaitannya dengan kehidupan sehari hari, bahkan hampir semua ilmu pengetahuan ada kaitannya dengan matematika. Oleh sebab itu, tidaklah berlebihan jika ada orang yang mengatakan bahwa matematika adalah ratu dari ilmu pengetahuan lainnya (queen of science). Karena pentingnya matematika dalam kehidupan manusia maka mata pelajaran matematika sudah diajarkan mulai tingkat Sekolah Dasar sampai Sekolah Menengah Atas.

Tujuan pembelajaran matematika dalam Peraturan Menteri Pendidikan Nasional No. 22 Tahun 2006 tanggal 23 Mei 2006 tentang Standar Isi adalah: (1) memahami konsep matematika, menjelaskan keterkaitan antarkonsep dan mengaplikasikan konsep atau algoritma secara luwes, akurat, efisien, dan tepat dalam pemecahan masalah. (2) Menggunakan penalaran pada pola dan sifat, melakukan manipulasi matematika dalam membuat generalisasi, menyusun bukti, atau menjelaskan gagasan dan pernyataan matematika. (3) Memecahkan masalah yang meliputi kemampuan memahami masalah merancang model matematika, menyelesaikan model, dan menafsirkan solusi yang diperoleh. (3) Mengkomunikasikan gagasan dengan simbol, tabel, diagram, atau media lain untuk memperjelas keadaaan atau masalah. (4) Memiliki sikap menghargai kegunaan matematika dalam kehidupan yaitu memiliki rasa ingin tahu, perhatian, dan minat dalam mempelajari matematika, serta sikap ulet dan percaya diri dalam pemecahan masalah.

Tujuan umum dalam pembelajaran matematika yang dicantumkan dalam NCTM (National Council of Teachers of Mathematics) (2000) yaitu: (1) komunikasi matematis (mathematical communication); (2) penalaran matematis (mathematical reasoning); (3) pemecahan masalah matematis (mathematical problem solving); (4) koneksi matematis (mathematical connections); (5) pembentukan sikap positif terhadap matematika (positive attitudes toward mathematics). Tetapi Menurut Ruseffendi (1998) bagian terbesar dari matematika yang dipelajari siswa di sekolah tidak diperoleh melalui eksplorasi matematik, tetapi melalui pemberitahuan (Ansari, 2012). Kenyataan di lapangan juga menunjukkan demikian, bahwa kondisi pembelajaran yang berlangsung di kelas membuat siswa pasif (product oriented education).
Salah satu tujuan pembelajaran dalam standar isi dan NCTM yang belum berhasil atau belum sesuai dengan harapan adalah kemampuan komunikasi matematis. Hal ini sesuai dengan temuan Ibrahim (2011) dan Aguspinal (2011) menunjukkan bahwa kemampuan komunikasi matematis siswa masih rendah, belum sesuai dengan apa yang diharapkan. Berbagai hasil penelitian cenderung mengemukakan bahwa sampai saat ini sebagian besar guru masih menggunakan pembelajaran biasa atau langsung yang masih berfokus pada guru.

Lomibao, Luna \& Namoco (2016) mengatakan bahwa kemampuan komunikasi matematis adalah kemampuan untuk mengekspresikan ide, menggambarkan, dan mendiskusikan konsep matematika secara koheren dan jelas. Kemampuan dalam menjelaskan dan membenarkan suatu prosedur dan proses baik secara lisan maupun tulisan. Menurut Prayitno, Suwarsono, \& Siswono (2013) komunikasi matematis adalah suatu cara peserta didik untuk menyatakan dan menafsirkan gagasan-gagasan matematika secara lisan maupun tertulis, baik dalam bentuk gambar, tabel, diagram, rumus, ataupun demonstrasi. Dari penjelasan ini maka kemampuan komunikasi matematis terdiri dari dua aspek yaitu komunikasi tulisan dan lisan, tetapi dalam penelitian ini peneliti hanya membatasi kemampuan komunikasi matematis pada aspek tulisan.

Berdasarkan hasil penelitian pendahuluan yang dilakukan peneliti terhadap salah satu sekolah dengan kategori sedang berdasarkan nilai UN, tepatnya di SMP Negeri 2 Mojolaban Sukoharjo dengan memberikan tes kemampuan komunikasi matematis diperoleh rata-rata 30,58. Artinya kemampuan siswa dalam menyelesaikan soal tersebut masih tergolong rendah. Adapun faktor rendahnya kemampuan komunikasi matematis di antaranya: Model pembelajaran yang dipakai selama ini masih bersifat trdisional dan cenderung monoton atau kurang bervariasi, ketidaksesuaian metode yang digunakan pada penyampaian mata pelajaran sehingga dapat mempengaruhi kemampuan komunikasi matematis, guru tidak memperhatikan variabel lain yang bisa berpengaruh terhadap kemampuan komuikasi matematis, siswa tidak menguasai materi prasyarat untuk mengikuti pembelajaran, dan tidak memadainya sarana dan prasarana di sekolah. Dari berbagai faktor di atas, faktor tidak bervariasinya model pembelajaran adalah faktor yang sangat berpengaruh terhadap kemampuan komunikasi matematis siswa. Oleh 
sebab itu, perlu dicari suatu model atau pendekatan yang bisa mengembangkan kemampuan komunikasi matematis siswa. Ansari (2012) mengungkapkan bahwa untuk mengembangkan kemampuan komunikasi matematis diperlukan suatu strategi atau model pembelajaran yang menuntut siswa agar berfikir, berdiskusi, dan menuliskan jawaban dari permasalahan yang diajukan oleh guru. Salah satu model pembelajaran yang bisa diterapkan untuk meningkatkan kemampuan komunikasi matematis tersebut adalah model pembelajaran problem solving (PS) karena model pembelajaran PS siswa dituntut untuk memecahkan masalah, mendiskusikan masalah untuk diselesaikan, dan menuliskan jawaban/solusi dari permasalahan yang diajukan oleh guru. Model pembelajaran PS pada pembelajaran matematika efektif ditinjau dari pencapaian kemampuan komunikasi matematis (Melianingsih \& Sugiman, 2015).

Polya (1957) melihat bahwa instruksi problem solving (PS) memiliki peluang yang besar dalam mengembangkan kemampuan/bakat matematika siswa. Dia menegaskan bahwa jika guru menantang keingintahuan siswanya dengan memberikan masalah sesuai dengan pengetahuan mereka dan membantu mereka dalam memecahkan masalah dengan merangsang pertanyaan, maka guru tersebut melatih siswa untuk berpikir. Oleh sebab itu, proses berpikir yang dilakukan oleh siswa dengan berdiskusi dengan temannya tentu akan membantu dalam memperbaiki kemampuan komunikasi matematis siswa. Menurut Mwelese dan Wanjala (2014) jika model pembelajaran PS diajarkan dengan benar kepada siswa maka: (1) siswa akan merenungkan dan mengingat kembali pengetahuan/pengalaman yang diperoleh sebelumnya, apakah dapat diterapkan dalam situasi/masalah saat ini; (2) mendukung tindakan pemecahan masalah dengan bukti atau argumen yang valid dan bukan sesuatu yang biasa. (3) Mempertimbangkan cara lain untuk memecahkan masalah tertentu. (4) Mencoba berbagai kondisi masalah untuk melihat apakah prosedur solusi yang sama akan dibutuhkan dalam penyelesaian masalah.

Selain model pembelajaran PS, faktor lain yang dapat mempengaruhi kemampuan komunikasi matematis adalah gender. Berdasarkan hasil-hasil penelitian menunjukkan bahwa perbedaan gender mempunyai andil untuk menerangkan profil seseorang dalam menyelesaikan masalah dan mengomunikasikan hasilnya walaupun perbedaan ini belum konsisten
(Wijaya, Sudjadi \& Riyadi 2016). Istilah gender mengacu pada atribut ekonomi, sosial, politik dan budaya, yang terkait dengan laki-laki dan perempuan. Sebagian besar masyarakat, perempuan sebagai kelompok memiliki akses yang lebih sedikit daripada laki-laki terhadap sumber daya, peluang dan pengambilan keputusan Bouanchaud (Commusion, 2010). Gender memiliki pengaruh yang besar terhadap hasil belajar siswa karena perbedaaan dari style dari laki-laki dan perempuan, sehingga mengakibatkan perbedaan hasil belajar dari perempuan dan laki-laki tersebut Mondoh (2000), Weis, Heikamp \& Trommsdorff (2013), Bosire, Mondoh \& Barmao (2008), dan Nizoloman (2013). Menurut Wood (1994) menyatakan bahwa perkembangan gender juga dapat dilihat dari perkembangan otak. Selanjutnya Wood menjelaskan bahwa pada laki-laki lebih berkembang otak kirinya sehingga dia mampu berpikir logis, berpikir abstrak, dan berpikir analitis, sedangkan pada perempuan lebih berkembang otak kanannya, sehingga dia cenderung beraktifitas secara artistic, holistik, imajinatif, berpikir intutif, dan beberapa kemampuan visual (Hodiyanto, 2014).

Berdasarkan uraian pendahuluan maka tujuan penelitian ini adalah untuk mengetahui: (1) manakah kemampuan komunikasi matematis siswa yang lebih baik antara model pembelajaran problem solving (PS) dan model pembelajaran langsung. (2) manakah kemampuan komunikasi matematis siswa yang lebih baik antara kelompok laki-laki dan perempuan. (3) interaksi antara model pembelajaran dan gender terhadap kemampuan komunikasi matematis.

\section{METODE}

Metode penelitian yang digunakan dalam penelitian ini adalah metode eksperimen jenis quasi experimental designs. Pada penelitian ini ada dua kelompok subjek penelitian yaitu kelompok eksperimen dan kelompok kontrol. Kelompok eksperimen mendapat perlakuan dengan model pembelajaran problem solving (PS) dan kelompok kontrol dengan perlakuan model pembelajaran langsung. Kedua kelompok diberikan tes akhir dengan menggunakan instrumen tes yang sama.

Populasi dalam penelitian ini adalah siswa kelas VII SMP Negeri 02 Mojolaban, Sukoharjo tahun ajaran 2015/2016. Penelitian ini bermaksud memberikan perlakuan pada sampel, selanjutnya peneliti ingin mengetahui efek atau pengaruh dari hasil perlakuan tersebut. 
Perlakuan yang dimaksud adalah pembelajaran dengan menggunakan model pembelajaran PS pada kelas eksperimen dan model pembelajaran langsung pada kelas kontrol. Teknik pengambilan sampel menggunakan teknik cluster random sampling. Sebelum pengambilan sampel terlebih dahulu diuji homogentas populasi tesebut. Berdasarkan hasil perhitungan diperoleh bahwa populasi memiliki variansi yang sama, selanjutnya penentuan sampel dilakukan dengan teknik cluster random sampling. Hasil penentuan sampel diperoleh kelas VIIC sebagai kelas eksperimen yang diberikan perlakuan dengan model pembelajaran problem solving dan kelas VIID sebagai kelas kontrol yang diberikan perlakuan dengan menggunakan model pembelajaran langsung. Rancangan yang digunakan dalam penelitian ini adalah factorial design disajikan pada Tabel 1.

Tabel 1. Desain Faktorial Penelitian

\begin{tabular}{lcc}
\hline \multirow{2}{*}{ Model } & \multicolumn{2}{c}{ Gender (B) } \\
\cline { 2 - 3 } Pembelajaran (A) & Laki-Laki & Perempuan \\
& $\left(\boldsymbol{b}_{1}\right)$ & $\left(\boldsymbol{b}_{2}\right)$ \\
\hline Problem Solving $\left(a_{1}\right)$ & $a_{1} b_{1}$ & $a_{1} b_{2}$ \\
Langsung $\left(a_{2}\right)$ & $a_{2} b_{1}$ & $a_{2} b_{2}$ \\
\hline
\end{tabular}

Keterangan :

$a_{1} b_{1}$ : kemampuan komunikasi matematis siswa laki-laki yang diajarkan model pembelajaran problem solving.

$a_{1} b_{2}$ : kemampuan komunikasi matematis siswa perempuan yang diajarkan model pembelajaran problem solving.

$a_{2} b_{1}$ : kemampuan komunikasi matematis siswa laki-laki yang diajarkan model pembelajaran langsung.

$a_{2} b_{2}$ : kemampuan komunikasi matematis siswa perempuan yang diajarkan model pembelajaran langsung.

Instrumen pengumpul data yang digunakan adalah tes kemampuan komunikasi matematis yang berbentuk essay sebanyak 4 soal. Sebelum digunakannya alat pengumpul data tersebut telah divalidasi ahli, validasi empiris, menghitung indeks kesukaran, menghitung daya pembeda, dan reliabelitasnya.

Dari penelitian yang dilakukan maka diperoleh data kuantitatif. Data kuantitatif didapat melalui tes kemampuan komunikasi matematis. Pengolahan data kuantitatif dilakukan melalui dua tahapan utama. Tahap pertama: menguji persyaratan statistik yang diperlukan sebagai dasar dalam pengujian hipotesis, yaitu uji normalitas sebaran data subyek sampel dan uji homogenitas varians. Tahap kedua: menguji ada atau tidak adanya perbedaan dari masingmasing kelompok dengan menggunakan uji ANAVA dua jalan dengan sel tak sama.

Uji prasyarat untuk uji univariat pada penelitian ini meliputi uji normalitas dan uji homogenitas variansi.

\section{Uji Normalitas}

Tujuan dilakukan uji normalitas adalah untuk menguji apakah data yang diperoleh berasal dari populasi berdistribusi normal atau tidak maka digunakan uji normalitas. Uji normalitas pada penelitian ini menggunakan metode Liliefors, dengan prosedur sebagai berikut:

Hipotesis

$H_{0}$ : Sampel berasal dari populasi yang berdistribusi normal

$H_{l}$ : Sampel tidak berasal dari populasi yang berdistribusi normal

Taraf Signifikansi $(\alpha=0,05)$

Sebelum diolah, setiap data $X$, diubah menjadi data baku $z$ dengan transformasi:

$\mathrm{z}_{\mathrm{i}}=\frac{\left(\mathrm{X}_{\mathrm{i}}-\overline{\mathrm{X}}\right)}{\mathrm{s}}$

Keterangan :

$\overline{\mathrm{X}}:$ ratan sampel

$\mathrm{S}$ : standar deviasi sampel

Kemudian dilakukan pengujian dengan statistik uji:

$L=\max \left|\mathrm{F}\left(\mathrm{z}_{\mathrm{i}}\right)-\mathrm{S}\left(\mathrm{z}_{\mathrm{i}}\right)\right|$

Keterangan:

$F\left(z_{i}\right)=P\left(Z \leq z_{i}\right) ; Z \sim N(0,1)$

$S\left(z_{i}\right)=$ proporsi cacah $Z \leq z_{i}$ terhadap seluruh cacah $z_{i}$

Daerah Kritik:

$D K=\left\{L \mid L>L_{\alpha ; n}\right\}$ dengan $\mathrm{n}$ adalah ukuran sampel

Keputusan Uji:

$H_{0}$ ditolak jika $L_{o b s} \in D K$, atau $H_{0}$ diterima jika $L$ obs $\notin D K$ (Budiyono, 2013)

\section{Uji Homogenitas}

Jika ternyata keduanya berdistribusi normal, dilanjutkan dengan uji homogenitas variansinya, yaitu uji F (Sugiyono, 2012).

Menghitung nilai $\mathrm{F}$ dengan rumus:

$F=\frac{\text { Varians terbesar }}{\text { Varians terkecil }}$ 
Penentuan homogenitas: Jika $F_{\text {hitung }}<$ $F_{\text {tabel, }}$ maka kedua variansi tersebut homogen, jika sebaliknya tidak homogen.

\section{Anava Dua Jalan dengan Sel tak sama}

Model Data

$X_{i j k}=\mu+\alpha_{i}+\beta_{j}+(\alpha \beta)_{i j}+\varepsilon_{i j k}$

dengan :

$X_{i j k}$ : data amatan ke-k pada baris ke-i dan kolom ke-j

$\mu \quad$ : rerata dari seluruh data amatan (rerata besar, grand mean)

$\alpha_{i} \quad$ : efek baris ke-i pada variabel terikat

$\beta_{\mathrm{j}} \quad$ : efek kolom ke-j pada variabel terikat

$(\alpha \beta)$ ij : interaksi efek baris ke-i dan efek kolom ke-j pada variabel terikat

eijk : deviasi data amatan terhadap rataan populasi yang berdistribusi normal dengan rataan 0 (disebut galat atau error).

Prosedur Uji Hipotesis

Hipotesis

$H_{0 A}: \alpha_{i}=0$ untuk setiap $i=1,2$

$H_{1 A}:$ paling sedikit ada $\alpha_{i}$ yang tidak nol

$H_{0 B}: \beta_{j}=0$ untuk setiap $j=1,2$

$H_{I B}$ : paling sedikit ada $\beta_{j}$ yang tidak nol

$H_{O A B}:(\alpha \beta)_{i j}=0$ untuk setiap $i=1,2$ dan $j=1,2$

$H_{I A B}$ : paling sedikit ada $(\alpha \beta)_{i j}$ yang tidak nol

Taraf signifikansi: 0,05

Komputasi

Notasi dan tata letak data pada Tabel 2.

Tabel 2. Notasi dan Tata Letak Data

\begin{tabular}{|c|c|c|c|}
\hline \multirow{2}{*}{\multicolumn{2}{|c|}{ Model Pembelajaran }} & \multicolumn{2}{|c|}{ Gender } \\
\hline & & $\begin{array}{c}\text { Tinggi } \\
\left(b_{1}\right)\end{array}$ & $\begin{array}{c}\text { Sedang } \\
\left(b_{2}\right)\end{array}$ \\
\hline $\begin{array}{l}\text { Model PS } \\
\left(a_{1}\right)\end{array}$ & $\begin{array}{l}\text { Cacah data } \\
\text { Jumlah } \\
\text { Data } \\
\text { Rataan } \\
\text { Jumlah } \\
\text { Kuadrat } \\
\text { Suku } \\
\text { Koreksi } \\
\text { Variansi }\end{array}$ & $\begin{array}{l}\sum_{11}^{n_{11}} X_{11} \\
\sum_{11} X_{11}^{2} \\
C_{11} \\
S S_{11}\end{array}$ & $\begin{array}{l}\sum_{12}^{n_{12}} X_{12} \\
\sum_{12} X_{12}^{2} \\
C_{12} \\
S S_{12}\end{array}$ \\
\hline $\begin{array}{l}\text { Model } \\
\text { Pembelajaran } \\
\text { Langsung } \\
\left(a_{2}\right)\end{array}$ & $\begin{array}{l}\text { Cacah data } \\
\text { Jumlah } \\
\text { Data } \\
\text { Rataan } \\
\text { Jumlah } \\
\text { Kuadrat } \\
\text { Suku } \\
\text { Koreksi } \\
\text { Variansi }\end{array}$ & $\begin{array}{l}\sum_{21}^{n_{21}} X_{21} \\
\bar{X}_{21} \\
\sum_{21}^{2} X_{21}^{2} \\
S S_{21}\end{array}$ & $\begin{array}{l}\sum_{22}^{n_{22}} X_{22} \\
\bar{X}_{22} \\
\sum_{C_{22}} X_{22}^{2} \\
S S_{22}\end{array}$ \\
\hline
\end{tabular}

Dengan $C_{i j}=\frac{\left(\sum X_{i j}\right)}{n_{i j}} \quad ; \quad S S_{i j}=\sum X_{i j}^{2}-C_{i j}$

Tabel 3. Rerata dan Jumlah Rerata

\begin{tabular}{clll}
\hline Faktor & \multicolumn{1}{c}{$\boldsymbol{b}_{\boldsymbol{1}}$} & $\boldsymbol{b}_{\mathbf{2}}$ & Total \\
\hline$a_{1}$ & $a b_{11}$ & $a b_{12}$ & $A_{1}$ \\
$a_{2}$ & $a b_{21}$ & $a b_{22}$ & $A_{2}$ \\
\hline Total & $B_{1}$ & $B_{2}$ & $G$ \\
\hline
\end{tabular}

Pada analisis variansi dua jalan dengan sel tak sama didefinisikan notasi-notasi sebagai berikut:

$n_{i j}$ : banyak data amatan pada sel $i j$

$\bar{n}_{h}$ : rerata harmonik frekuensi seluruh sel $=$ $\frac{p q}{\sum_{i, j} \frac{1}{n_{i j}}}$

$N=\sum_{i, j} n_{i j}$ : banyaknya seluruh data amatan

$S S_{i j}=\sum_{k} X_{i j k}^{2}-\frac{\left(\sum_{k} X_{i j k}\right)^{2}}{n_{i j}}:$ jumlah kuadrat deviasi data amatan pada sel $i j$ $\overline{A B_{i j}} \quad$ : rerata pada sel $i j$

$A i=\sum_{i} \overline{A B}_{i j}:$ jumlah rerata pada baris ke- $i$

$B j=\sum_{j} \overline{A B}_{i j}$ : jumlah rerata pada kolom ke-j

$G=\sum_{i, j} \overline{A B}_{i j}:$ jumlah rerata semua sel

Komponen Jumlah Kuadrat

Didefinisikan:

$$
=\frac{G^{2}}{p q} ;(2)=\sum_{i, j} S S_{i j} ;(3)=\sum_{i} \frac{A_{i}^{2}}{q} ;
$$

$=\sum_{j} \frac{B_{i}^{2}}{p} ;(5)=\sum_{i, j} \overline{A B}_{i j}^{2}$

Jumlah Kuadrat (JK)

$J K A=\bar{n}_{h}\{(3)-(1)\}$

$J K B=\bar{n}_{h}\{(4)-(1)\}$

$J K A B=\bar{n}_{h}\{(1)+(5)-(3)-(4)\}$

$J K G=(2)$

$J K T=J K A+J K B+J K A B+J K G$

Dengan :

$J K A \quad$ : jumlah kuadrat baris

$J K B \quad$ : jumlah kuadrat kolom

$J K A B$ : jumlah kuadrat interaksi

$J K G \quad$ : jumlah kuadrat galat 
$J K T \quad$ : jumlah kuadrat total

Derajat Kebebasan $(d k)$

$$
\begin{array}{ll}
d k A & =p-1 \\
d k B & =q-1 \\
d k A B & =(p-1)(q-1) \\
d k G & =N-p q \\
d k T & =N-1
\end{array}
$$

Rataan Kuadrat $(R K)$

$$
\begin{aligned}
R K A & =\frac{J K A}{d k A} \\
R K B & =\frac{J K A}{d k B} \\
R K A B & =\frac{J K A}{d k A B} \\
R K G & =\frac{J K A}{d k G}
\end{aligned}
$$

\section{Statistik Uji}

Statistik uji analisis variansi dua jalan dengan sel tak sama adalah:

Untuk $H_{0 A}$ adalah $F_{a}=\frac{R K A}{R K G}$ yang merupakan nilai variabel random yang berdistribusi $\mathrm{F}$ dengan derajat kebebasan $p-1$ dan $N-p q$.

Untuk $H_{O B}$ adalah $F_{b}=\frac{R K B}{R K G}$ yang merupakan nilai variabel random yang berdistribusi $F$ dengan derajat kebebasan $q-1$ dan $N-p q$.

Untuk $H_{0 A B} \quad$ adalah $\quad F_{a b}=\frac{R K A B}{R K G} \quad$ yang merupakan nilai variabel random yang berdistribusi $\mathrm{F}$ dengan derajat kebebasan $(p-$ 1) $(q-1)$ dan $N-p q$.

Daerah Kritik

Untuk masing - masing nilai $F$, daerah kritiknya adalah sebagai berikut:

a. Daerah kritik untuk $F_{a}$ adalah $D k_{a}=\{F \mid F$ $\left.>F_{\alpha ; p-1, N-p q}\right\}$

b. Daerah kritik untuk $F b$ adalah $D k_{b}=\{F \mid F$ $\left.>F_{\alpha ; q-1, N-p q}\right\}$

c. Daerah kritik untuk $F_{a b}$ adalah $D k_{a b}=\{F \mid$ $\left.F>F_{\alpha ;(p-I)(q-I), N-p q}\right\}$

Keputusan Uji

$H_{0}$ ditolak jika $F_{o b s} \in D K$.

Rangkuman Analisis Variansi pada Tabel 4.
Tabel 4. Rangkuman Analisis Variansi Dua Jalan

\begin{tabular}{llllll}
\hline \multicolumn{1}{c}{ Sumber } & \multicolumn{1}{c}{$\boldsymbol{J K}$} & \multicolumn{1}{c}{$\boldsymbol{d} \boldsymbol{k}$} & \multicolumn{1}{c}{$\boldsymbol{R} \boldsymbol{K}$} & $\boldsymbol{F}_{\boldsymbol{o b s}}$ & $\boldsymbol{F} \boldsymbol{\alpha}$ \\
\hline Baris $(A)$ & $J K A$ & $p-1$ & $R K A$ & $F a$ & $F^{*}$ \\
Kolom $(B)$ & $J K B$ & $q-1$ & $R K B$ & $F b$ & $F^{*}$ \\
Interaksi $(A B)$ & $J K A B$ & $(p-1)(q-1)$ & $R K A B$ & $F a b$ & $F^{*}$ \\
Galat $(G)$ & $J K G$ & $N-p q$ & $R K G$ & - & - \\
Total & $J K T$ & $N-1$ & - & - & - \\
\hline
\end{tabular}

(Budiyono, 2013)

\section{HASIL DAN PEMBAHASAN}

Data kemampuan awal siswa yang dimaksud dalam penelitian ini adalah data kemampuan komunikasi matematika. Data kemampuan awal kemampuan awal komunikasi matematis peserta didik diperoleh dari tes kemampuan komunikasi matematis sebelum perlakuan. Data tersebut digunakan untuk uji keseimbangan. Uji keseimbangan dilakukan menggunakan analisis uju t dua pihak. Sebelum dilakukan uju t, terlebih dahulu dilakukan uji prasyarat, yaitu data harus berdistribusi normal dan homogen.

\section{Uji Keseimbangan}

Dalam melakukan uji normalitas data kemampuan awal kemampuan komunikasi matematis peserta didik menggunakan uji Lilliefors. Rangkuman uji normalitas univariat data kemampuan awal sebagai berikut.

Tabel 5. Uji Normalitas Data Kemampuan Awal Komunikasi Matematis

\begin{tabular}{lcccc}
\hline Kelompok & $\boldsymbol{n}$ & $\boldsymbol{L}_{\boldsymbol{o b s}}$ & $\boldsymbol{L}_{a ; \boldsymbol{n}}$ & $\begin{array}{c}\text { Keputusan } \\
\mathbf{U j i}\end{array}$ \\
\hline Eksperimen & 32 & 0,1283 & 0,1556 & $H_{0}$ diterima \\
\hline Kontrol & 32 & 0,1237 & 0,1556 & $H_{0}$ diterima \\
\hline
\end{tabular}

Berdasarkan hasil analisis pada Tabel 5 , diperoleh semua sampel memiliki statistik uji $L_{o b s} \leq L_{a ; n}$ akibatnya $L_{o b s} \notin D K$, sehingga dapat disimpulkan untuk taraf signifikansi $5 \%$ semua sampel berasal dari populasi yang berdistribusi normal univariat. Selanjunya akan diuji homogenitas dari kemampuan komunikasi matematis tersebut. Rangkuman uji homogenitas univariat data awal kemampuan komunikasi matematis pada Tabel 6.

Berdasarkan Tabel 5 dan Tabel 6 di atas diperoleh bahwa data awal kemampuan komunikasi matematis siswa berdistribusi normal dan homogen maka uji keseimbangan dilanjutkan dengan menggunakan uji t. Hasil perhitungan uji t dapat dilihat pada Tabel 7. 
Jurnal Riset Pendidikan Matematika, 4 (2), 2017 - 225

H. Hodiyanto

Tabel 6. Uji Homogenitas Data Awal Kemampuan Komunikasi Matematis pada Kelompok Penelitian

\begin{tabular}{cccccc}
\hline Kemampuan & \multicolumn{2}{c}{ Varians } & \multirow{2}{*}{$\boldsymbol{F}_{\text {hitung }}$} & $\boldsymbol{F}_{\text {tabel }}$ & \multirow{2}{*}{ Keterangan } \\
\cline { 2 - 4 } $\begin{array}{c}\text { Komunikasi } \\
\text { Matematis }\end{array}$ & Eksperimen & Kontrol & & Homogen \\
\cline { 2 - 3 }
\end{tabular}

$\alpha=5 \%$

Tabel 7. Uji Keseimbangan Data Awal Kemampuan Komunikasi Matematis pada Kelompok Penelitian

\begin{tabular}{|c|c|c|c|c|c|c|}
\hline \multirow{3}{*}{$\begin{array}{c}\text { Kemampuan } \\
\text { Komunikasi Matematis }\end{array}$} & \multirow{2}{*}{$\begin{array}{l}\text { Nilai } \\
\text { Ideal }\end{array}$} & \multicolumn{2}{|c|}{$\begin{array}{c}\text { Nilai Rerata Kelompok } \\
\text { Penelitian }\end{array}$} & \multirow{2}{*}{$\begin{array}{c}\text { Nilai } \\
t_{\text {hitung }}\end{array}$} & \multirow{2}{*}{$\begin{array}{l}\text { Nilai } \\
t_{\text {tabel }}\end{array}$} & \multirow{2}{*}{$\begin{array}{c}\text { Keputusar } \\
H_{0}\end{array}$} \\
\hline & & Eksperimen & Kontrol & & & \\
\hline & 100 & 35,94 & 30,58 & 1,34 & 2,00 & Diterima \\
\hline
\end{tabular}

$\alpha=5 \%$

Tabel 8 Uji Normalitas Data Postest Kemampuan Komunikasi Matematis Pada Kelompok Penelitian

\begin{tabular}{llllll}
\hline & Kelompok & $\boldsymbol{L}_{\boldsymbol{o b s}}$ & $\boldsymbol{L}_{a ; n}$ & Kesimpulan & Keterangan \\
\cline { 2 - 6 } Kemampuan Komunikasi Matematis & Eksperimen & 0,1551 & 0,1556 & $H_{0}$ Diterima & Normal \\
\cline { 2 - 6 } & Kontrol & 0,1144 & 0,1556 & $H_{0}$ Diterima & Normal \\
\cline { 2 - 6 } & Laki-Laki & 0,1618 & 0,1451 & $H_{0}$ Diterima & Normal \\
\cline { 2 - 6 } & Perempuan & 0,1516 & 0,1003 & $H_{0}$ Diterima & Normal \\
\hline
\end{tabular}

$\alpha=5 \%$

Tabel 9 Uji Homogenitas Data Postest Kemampuan Komunikasi Matematis pada Kelompok Penelitian

\begin{tabular}{lllllll}
\hline & Kelompok & Varians & $\boldsymbol{F}_{\text {hitung }}$ & $\boldsymbol{F}_{\text {tabel }}$ & Keterangan \\
\cline { 2 - 4 } Kemampuan Komunikasi Matematis & Eksperimen & 398,31 & & 1.07 & 4,00 & \multirow{2}{*}{ Homogen } \\
\cline { 2 - 4 } & Kontrol & 428,13 & & & \\
\cline { 2 - 4 } & Laki-Laki & 340,47 & \multirow{2}{*}{1,61} & \multirow{2}{*}{4,00} & \multirow{2}{*}{ Homogen } \\
\cline { 2 - 4 } & Perempuan & 549.82 & & & &
\end{tabular}

$\alpha=5 \%$

Tabel 10 Analisis Varians Dua Jalan Kemampuan Komunikasi Matematis

\begin{tabular}{lcccccc}
\hline Sumber & JK & dk & RK & $\boldsymbol{F}_{\text {hitung }}$ & $\boldsymbol{F}_{\text {tabel }}$ & Kesimpulan \\
\hline Baris (A) & 5346.409 & 1 & 5346.409 & 12.993 & 4.001 & $H_{0 A}$ Ditolak \\
\hline Kolom (B) & 1074.317 & 1 & 1074.32 & 2.611 & 4.001 & $H_{0 B}$ Diterima \\
\hline Interaksi (AB) & 792.62 & 1 & 792.621 & 1,926 & 4.001 & $H_{0 B}$ Diterima \\
\hline Galat & 24689.698 & 60 & 411.495 & - & - & - \\
\hline Total & 31903.045 & 63 & - & - & - & - \\
\hline$\alpha=5 \%$ & & & & & &
\end{tabular}

Dari Tabel 7 dengan tingkat alfa $5 \%$ diperoleh bahwa $t_{\text {hitung }}$ berada pada daerah penerimaan sehingga $H_{0}$ tidak ditolak, yang arti-nya tidak terdapat perbedaan kemampuan awal siswa dalam kemampuan komunikasi mate-matisnya. Oleh sebab itu, dapat disimpulkan bahwa kemampuan komunikasi matematis awal siswa dalam keadaan seimbang.

Dalam penelitian ini, untuk menjawab rumusan masalah sesuai dengan tujuan penelitian maka digunakan anava dua jalan. Sebelum dilakukan uji anava, terlebih dahulu dilakukan uji pra syarat. Adapun uji pra syarat dalam anava yaitu data harus berdistribusi normal dan homogen. Rangkuman uji normalitas dan homogenitas dapat dilihat pada Tabel 8 dan Tabel 9.

Berdasarkan Tabel 8 dan Tabel 9 dengan tingkat alpha 5\% diperoleh bahwa data kemampuan komunikasi matematis siswa di setiap kelompok penelitian berdistribusi normal dan memiliki variansi yang sama (homogen), artinya pra syarat uji analisis variansi dua jalan (anava) untuk uji hipotesis sudah terpenuhi. Oleh sebab itu, uji hipotesis akan dilanjutkan dengan anava dengan sel tak sama. Rangkuman hasil perhitungan anava dapat dilihat pada Tabel 10.

Berdasarkan hasil perhitungan anava pada Tabel 10 diperoleh bahwa $F_{\text {hitung }}$ pada kelom- 


\section{Jurnal Riset Pendidikan Matematika, 4 (2), 2017 - 226}

H. Hodiyanto

pok baris berada pada daerah kritis, daerah penolakan sehingga $H_{0 A}$ ditolak yang artinya terdapat perbedaan kemampuan komunikasi matematis siswa yang diajarkan model pembelajaran problem solving dengan siswa yang diajarkan dengan model pembelajaran langsung. Jika ingin melihat manakah kemampuan komunikasi matematis yang lebih baik antara model pembelajaran problem solving dan model pembelajaran langsung maka dapat dilihat dari rerata marginalnya. Rerata marginal kemampuan komunikasi matematis kelompok siswa yang diberikan model pembelajaran problem solving adalah 50,38 lebih besar dari pada rerata marginal kemampuan komunikasi matematis kelompok siswa yang diberikan model pembelajaran langsung yaitu 37,50. Artinya, kemampuan komunikasi matematis kelompok siswa yang diberikan model pembelajaran problem solving lebih baik dari pada marginal kemampuan komunikasi matematis kelompok siswa yang diberikan model pembelajaran langsung. Hal ini terjadi karena model pembelajaran problem solving siswa diberikan masalah untuk diselesaikan dan dalam penyelesaian masalah tersebut tentu siswa harus berdiskusi dengan teman kelompoknya sehingga tejadi komunikasi antar teman kelompoknya berbeda dengan model pembelajaran langsung, siswa hanya menerima materi yang disampaikan oleh gurunya. Selain itu, penyelesaian masalah dalam model pembelajaran PS tidak mutlak harus memiliki satu jawaban, tetapi siswa juga dituntut agar kreatif dalam menemukan ide, solusi, maupun langkahlangkah penyelesain, sebaliknya dalam model pembelajaran langsung siswa hanya diberikan tes atau kuis setelah penyampaian materi. Hasil penelitian ini juga sesuai dengan pendapat Mwelese \& Wanjala (2014) bahwa model pembelajaran PS memberikan keluasaan kepada siswa untuk berinteraksi tidak hanya dengan guru tetapi juga dengan temannya berbeda dengan model pembelajaran langsung terjadinya interaksi hanya satu arah yaitu antar siswa dan guru. Model pembelajaran PS lebih bermakna dari pada model pembelajaran langsung karena siswa dalam memahami materi berdasarkan masalah yang diajukan oleh guru sehingga siswa mampu menemukan sendiri konsep yang akan dipelajari, sedangkan pada model pembelajaran langsung, siswa langsung diberikan materi atau siswa hanya menerima lansung materi dari guru tanpa menemukannya sendiri dan setelah penyampaian materi siswa diberi tes sebagaimana pendapat Ausubel (1978) bahwa pembelajaran dikatakan bermakna jika siswa diberikan keleluasaan dalam mengkontruksikan pemahaman sebelumnya untuk memahami materi yang akan dipelajari, artinya pembelajaran akan lebih bermakna jika siswa tidak hanya menerima saja tetapi menemukan konsep yang akan dipelajari. Menurut Temuan ini sesuai dengan hasil penelitian Hodiyanto (2016) bahwa kemampuan komunikasi matematis siswa yang diajarkan dengan model pembelajaran problem solving dengan pendekatan PMR lebih baik dari pada kemampuan komunikasi matematis siswa yang diajarkan dengan model pembelajaran langsung. Hasil penelitian Ali, Hukamdad, Akhter, \& Khan (2010) dan Perveen (2010) diperoleh bahwa model pembelajaran PS lebih efektif dari pada model pembelajaran biasa atau langsung untuk meningkatkan hasil belajar siswa.

Hasil perhitungan anava antar kolom pada Tabel 10 diperoleh bahwa $F_{\text {hitung }}$ pada kelompok kolom berada di luar daerah kritis sehingga $H_{0 B}$ tidak ditolak yang artinya tidak terdapat perbedaan kemampuan komunikasi matematis antara siswa laki-laki mapun perempuan. Jika dilihat dari rerata marginal kemampaun komunikasi matematis siswa laki-laki sebesar 41,03 tidak jauh berbeda dengan kemampuan komunikasi matematis siswa perempuan yaitu 46, 82. Dalam model pembelajaran PS maupun model pembelajaran langsung, aktivitas siswa perempuan dan laki-laki tidak berbeda secara signifikan walaupun dalam diskusi ada beberapa siswa perempuan yang lebih aktif. Masalah yang diajukan oleh guru adalah masalah yang berkaitan dengan bentuk aljabar sehingga tidak ada perbedaan yang signifikan kemampuan komunikasi matematis pada siswa laki-laki dan perempuan. Berbagai hasil penelitian menunjukkan perbedaan hasil belajar siswa laki-laki dan perempuan pada materi yang berkaitan dengan spasial (Kondor, 2014; Pietsch \& Jansen, 2012). Hasil penelitian ini sesuai temuan Munandar (Hodiyanto, 2014) bahwa tidak ditemukan perbedaan yang nyata antara siswa perempuan dan siswa laki-laki pada tes inteligensi, kreatifitas, daya ingatan, dan prestasi sekolah; anak laki-laki dan perempuan prestasinya setara dalam semua tes. Selanjutnya, jika dilihat dari interaksi antar baris dan kolom diperoleh bahwa $F_{\text {hitung }}$ pada interaksi berada di luar daerah kritis sehingga $H_{0 A B}$ tidak ditolak yang artinya tidak terdapat interaksi antara model pembelajaran dan siswa laki-laki maupun perempuan terhadap kemampuan komunikasi matematis. Tidak adanya interaksi ini disebabkan tidak ada 
perbedaan kemampuan komunikasi matematis siswa antara laki-laki dan perempaun di setiap model pembelajaran, artinya kemampuan komunikasi matematis baik siswa laki-laki maupun perempaun yang diajarkan dengan model pembelajaran PS lebih baik dari pada model pembelajaran langsung. Rangkuman rerata dari setiap kelompok penelitian dapat dilihat pada Gambar 1.

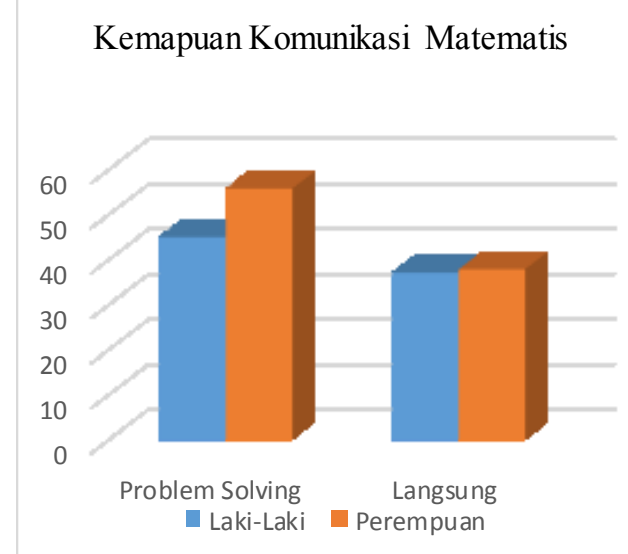

Gambar 1. Rangkuman Rerata Dari Setiap Kelompok Penelitian

Berdasarkan Gambar 1, kemampuan komunikasi matematis siswa di setiap model pembelajaran, siswa perempuan memiliki kemampuan komunikasi lebih tinggi dari pada kemampuan komunikasi matematis siswa lakilaki walapun perbedaan tersebut tidak signifikan, sehingga berdasarkan hasil perhitungan anova menunjukkan tidak adanya perbedaan kemampuan komunikasi matematis pada kelompok perempuan dan laki-laki tersebut.

\section{SIMPULAN DAN SARAN}

\section{Simpulan}

Berdasarkan hasil penelitian, pembahasan, dan kajian teori maka dalam penelitian ini dapat disimpulkan sebagai berikut: (1) Kemampuan komunikasi matematis siswa yang diajarkan dengan model pembelajaran problem solving lebih baik dari pada kemampuan komunikasi matematis siswa yang diajarkan dengan model pembelajara langsung. (2) tidak terdapat perbedaan kemampuan komunikasi matematis antara siswa laki-laki mapun perempuan. (3) tidak terdapat interaksi antara model pembelajaran dan gender terhadap kemampuan komunikasi matematis.

\section{Saran}

Penulis berharap agar para peneliti atau calon peneliti dapat meneruskan atau mengem- bangkan penelitian menggunakan model pembelajaran problem solving dengan pendekatan open ended agar masalah yang diberikan kepada siswa berupa masalah open ended sehingga mampu memberikan peningkat-an yang lebih baik. Selain itu, sebaiknya masalah yang diajukan dalam model pembelajaran PS adalah masalah kontekstual agar lebih mudah dipahami oleh siswa. Selanjutnya, calon peneliti dapat mengembangkan model pembelajaran problem solving dengan tinjauan yang lain seperti dari tingkat kecerdasan maupun intelegensi. Model pembelajaran PS membutuhkan waktu yang lama sehingga seorang guru ataupun peneliti harus mampu mengatur waktu sebaik-baiknya. Hasil penelitian ini juga dapat dijadi-kan dasar pengembangan model pembelajaran inovatif berbasis PS yang dapat meningkatkan kemampuan komunikasi matematis siswa maupun mahasiswa. Selain itu menjadi dasar pengembangan soal matematika berbasis kemampuan komunikasi matematis.

\section{DAFTAR PUSTAKA}

Aguspinal. (2011). Peningkatan kemampuan berpikir kreatif dan komunikasi matematis siswa sma melalui pendekatan openended dengan strategi group-to-group. Tesis. Universitas Pendidikan Indonesia, Bandung.

Ali, R., Hukamdad., Akhter, A., \& Khan, A. (2010). Effect of using solving method in teaching mathematics on the achivement of mathematics students. CCSE Asian Social Science, 6(2), 67-72.

Ansari, B. I. (2012). Komunikasi matematik dan politik. Banda Aceh: Yayasan Pena.

Ausubel, D. (1978). Learning as contructing meaning. In N. Entwistle (Ed.), New Directions in Educational Psychology I Learning and Teaching. London: The Falmer Press.

Bosire, J., Mondoh, H. \& Barmao, A. (2008). Effect of streaming by gender on student achievement in mathematics in secondary schools in Kenya. South African Journal of Education. 28. 595-607

Budiyono. (2013). Statistika untuk penelitian edisi II. Surakarta: UPT UNS Press.

Commusion, E. (2010). Gender differences in educational outcomes: Study on the measures taken and the current situation in Europe. EACEA P9 Eurydice. 


\section{Jurnal Riset Pendidikan Matematika, 4 (2), 2017 - 228}

H. Hodiyanto

Hodiyanto. (2014). Meningkatkan kemampuan berpikir kreatif siswa melalui pembelajaran pemecahan masalah ditinjau dari gender pada materi himpunan. Jurnal Pendidikan Informatika dan Sains, 3 (1), 27-41. Retrieved from http://journal.ikippgriptk.ac.id/index.php/s aintek/article/view/203/0.

Hodiyanto. (2016). Eksperimentasi model pembelajaran problem posing dan problem solving dengan pendekatan PMR terhadap prestasi belajar dan kemampuan komunikasi matematis ditinjau dari kreativitas siswa kelas VII SMP Negeri di Kabupaten Sukoharjo. Jurnal Pembelajaran Matematika, 4 (2), 199214. Retrieved from https://jurnal.uns.ac.id/jpm/article/ view/10866/9742.

Ibrahim. (2011). Peningkatan kemampuan komunikasi, penalaran, dan pemecahan masalah matematis serta kecerdasan emosional melalui pembelajaran berbasismasalah pada siswa sekolah menengah. Disertasi. Universitas Pendidikan Indonesia, Bandung.

Kondor, R. N. (2014). Importance of spatial visualization skills in Hungary and Turkey: Comparative studies. Annales Mathematicae et Informaticae, 43, 171181

Lomibao, L. S., Luna, C. A. \& Namoco, R. A. (2016). The influence of mathematical communication on students' mathematics performance and anxiety. American Journal of Educational Research, 4 (5), 378-382.

Melianingsih, N., \& Sugiman, S. (2015). Keefektifan pendekatan open-ended dan problem solving pada pembelajaran bangun ruang sisi datar di SMP. Jurnal Riset Pendidikan Matematika, 2(2), 211 223.

doi:http://dx.doi.org/10.21831/jrpm.v2i2. 7335

Mondoh, H. O. (2000). A comparison of activities carried out by boys and girls during their free time in relation to their achievement in mathematics. A case of Eldoret municipality, Kenya. Journal of Education and Human Resources, 1, 4956.
Mwelese, J. K. \& Wanjala, M. S. M. (2014). Effect of problem solving strategy school students' achievement in circle geometry in Emuhaya District of Vihiga County. Journal of Education, Arts and Humanities, 2, 18-26.

Nizoloman, O. N. (2012). Relationship between mathematical ability and achievement in mathematics among secondary school students in bayelsa state Nigeria. Procedia Social and Behavioral sciences. 106, 2230-2240.

NCTM. (2000). Principles and standards for school mathematics. The United State of America.

Perveen, K. (2010). Effect of the problemsolving approach on academic achievement of students in mathematics at th secondary level. Contemporary Issue In Education Research, 3(3), 9-14.

Pietsch, S. \& Jansen, P. (2012). Different mental rotation performance in students of music, sport and education, learning and individual differences, 22, 159-163.

Polya, G. (1957). How to solve it. Princeton N.J: Princeton University Press. SMASSE Project (1998). Baseline Studies Document. An unpublished paper presented during national INSET at KSTC, Nairobi.

Prayitno, S., Suwarsono, \& Siswono, T. Y. (2013). Identifikasi indikator kemampuan komunikasi matematis siswa dalam menyelesaikan soal matematika berjenjang pada tiap-tiap jenjangnya. Konferensi Nasional Pendidikan Matematika V, 27-30 Juni 2013. Malang: Universitas Negeri Malang.

Sugiyono. (2012). Statistika untuk penelitian. Bandung: Alfabeta.

Weis, M., Heikamp, T. \& Trommsdorff, G. (2013). Gender differences in school achievement: The role of self-regulation. Frontiers in Psychology, 4, 1-10.

Wijaya, H. P. M., Sudjadi, I. \& Riyadi. (2016). Kemampuan komunikasi matematis siswa sesuai dengan gender dalam pemecahan masalah pada materi balok dan kubus (Studi kasus pada siswa SMP Kelas VIII SMP Islam Al-Azhar 29 Semarang). Jurnal Elektronik Pembelajaran Matematika, 4(9), 778-788. 